\title{
Effect of aggregate type on moisture susceptibility of modified cold recycled mix asphalt: evaluation by mechanical tests and Surface Free Energy method
}

\author{
Hassan Latifi, Nahid Amini \\ Department of Civil Engineering, Science and Research Branch, Islamic Azad University, Tehran, Iran \\ Hassan.latifi@srbiau.ac.ir, Nabid.amini@srbiau.ac.ir
}

\begin{abstract}
There are deficiencies associated with cold mix asphalts, specifically, cold recycled mix asphalts in comparison with hot mix asphalt or hot recycled mix asphalt such as higher moisture susceptibility. Moisture damage of asphalt mixtures is inversely related to the bond quality between aggregates and binder. In this study, Portland cement (PC) and acryl polymer (AP) additives were employed to improve this bond. The effectiveness of used additives in improving the moisture susceptibility of cold recycled mix asphalt was examined using Surface Free Energy (SFE) method. Indirect Tensile Strength test and Dynamic Modulus test were performed to validate SFE method results. Moreover, scanning electron microscope (SEM) images were obtained for better understanding of mixture's microstructure. Also, effect of using granite, limestone and recycled asphalt pavement (RAP) aggregates was evaluated. The findings showed that cement and acryl polymer additives improved resistance of different studied mixtures, specifically, cold recycled mix asphalt against moisture damage by improving the adhesion between aggregate and asphalt. Considering effect of aggregates on moisture susceptibility, limestone-mixtures had the highest resistance while the RAPmixtures performed the worst among the three. Finally, it was shown that results of SFE method were compatible with the mechanical tests in predicting moisture damage.
\end{abstract}

KEYWORDS. Cold recycling; Acryl polymer; Portland cement; Moisture susceptibility; Surface free energy.
OPEN ACCESS

Citation: Latifi, H., Amini, N., Effect of aggregate type on moisture susceptibility of modified cold recycled mix asphalt: evaluation by mechanical tests and Surface Free Energy method, Frattura ed Integrità Strutturale, 52 (2020) 211-229.

Received: 21.01 .2020

Accepted: 17.02 .2020

Published: 01.04.2020

Copyright: (C) 2020 This is an open access article under the terms of the CC-BY 4.0, which permits unrestricted use, distribution, and reproduction in any medium, provided the original author and source are credited.

\section{INTRODUCTION}

$\mathrm{I}$ n many cases, one of the best alternatives to hot mix asphalts (HMAs) are the cold mix asphalts which have comparatively lower costs and are more environmentally-friendly due to their reduced hydrocarbon emissions, energy consumption, and toxic fumes as well as the ease of paving and repairing at rural roads far from a hot mix plant [1]. 
Generally, cold mix asphalt is liquefied with emulsified asphalt besides heat. Current practice of moisture sensitivity testing on cold recycled mix asphalts (CRMA) using an emulsified asphalt recycling agent, consist of either Marshal stability, AASHTO T 245 (ASTM D6927), or indirect tensile strength, AASHTO T 283 (ASTM D4867). Hveem stability, as outlined in AASHTO T 246 (ASTM D1560), is rarely used [2,3]. One of the main challenges of using cold mix asphalt (CMA) is its higher moisture susceptibility [4]. The quality of bond between asphalt binder and aggregates could directly represent the moisture induced damage of asphalt mixtures. Therefore, to improve moisture sensitivity of cold mix asphalt (CMA), it is necessary to improve the bond between recycled/virgin aggregates and binder in the CMAs. The adhesion bonds in this study were evaluated using surface free energy (SFE) method. This method enables us to investigate aggregate-binder bond in dry and wet conditions and consequently evaluate the moisture susceptibility of asphalt mixtures [5]. The aggregate-binder bond could be improved by using additives, improving the curing process, etc [6,7]. In cold recycled asphalt mixtures, chemical additives such as cement, lime, polymers and also mineral additives which have become more important in terms of their economic properties over the last few years [8], may be used with recycling agents such as asphalt emulsion to improve early strength gain and resistance against rutting and moisture of CRMAs. A composite containing cement, fine and coarse aggregates and water, it is highly durable and has the long life potential, with little or no maintenance [9]. In asphalt mixtures, Portland cement (PC) content should be held low, typically between $0.25 \%$ and $1 \%$ of asphalt binder's weight, to prevent brittle behavior of the mixture. The least acceptable ratio of the asphalt residue to cement is 3 to $1[10]$.

On the other hand, mechanical properties of CRMAs such as rutting, thermal cracking and traffic-induced stresses resistance, could be improved by polymer modification of asphalt emulsions [11]. Generally, polymer modification is recommended for CRMAs because of the following improvements in the mixture performance [11]:

- Better performance against bleeding and rutting i.e. stiffer at high temperatures;

- Better performance against shelling and cracking i.e. less brittle at low temperatures;

- Better performance against early chip loss, raveling and delamination i.e. more adhesive;

- Better performance against chip loss and cracking i.e. more elastic - fatigue resistant;

- Less susceptible to oxidative aging (raveling, cracking); and,

- Less susceptible to moisture damage.

\section{Surface Free Energy method}

The main reason of CRMA weakness against moist condition is decreased adhesion and cohesion properties [7] of mixture ingredients. To date, the general practice to evaluate the asphaltic mixture resistance against moisture damage is to use mechanical tests (ITS and DM) at dry and wet conditions. While these mechanical tests could provide a general comprehension of the asphalt mixture's behavior at moist condition, the results of which is affected by other effective parameters such as the adhesion bond parameter. Despite that the classic tests give a comprehensive understanding about the asphalts' behavior, they have some deficiencies such as:

- Low compatibility with the real loading and pavement conditions

- Inability to consider the constitutive material properties alongside with outer destructive mechanisms

- Time consuming

The method could measure the adhesion bond between aggregate and binder and the cohesion of binder because of their importance in moisture susceptibility of asphalt mixtures. SFE parameters of binder and aggregate are important properties that could be used to study of the moisture susceptibility of asphalt mixture. This method determines the tendency of mixture for replacing the asphalt binder with water by quantifying the adhesion bond between asphalt binder and aggregates in presence of a third material namely water. Within the mechanism behind this replacement stripping takes place in asphalt mixtures. The relative calculations are based on the basic thermodynamic laws. This method provides a better resistant mixture against moisture distresses by selection of proper material and their mix design [12].

\section{Statement and objectives}

A chart of the subjects of this study is shown in Fig. 1. Three different aggregates including granite, limestone and recycled asphalt pavement (RAP) were used to produce HMAs, HRMAs, CMAs, CRMAs. Portland cement and acryl polymer (AP) were used as additives in CRMAs and CMAs to improve their resistance against moisture damage. The moisture susceptibilities were determined using the SFE method and then results were validated with the indirect tensile strength (ITS) and the dynamic modulus (DM) tests. Finally, scanning electron microscope (SEM) images were taken for better understanding of the modified-CRMA's microstructure. Another applied factor for evaluating the compatibility and moisture susceptibility of materials in this study was a method (From SFE and DM) which determined the aggregate surface area $(\%)$ in contact with water per cycle of DM test $(\mathrm{P})$. 
The main objectives of this research are:

- Evaluating the moisture susceptibility of cement- modified CRMA and the effect of using acryl polymer (AP) in combination with PC.

- Comparing SFE test results with classic mechanical tests (ITS and DM) to evaluate validation of SFE in prediction of moisture susceptibility of CMAs.

- Utilizing the SFE method to determine the best mix design in the production of studied CMAs.

Tests were performed in both dry and wet conditions on different combinations of additives and aggregates.

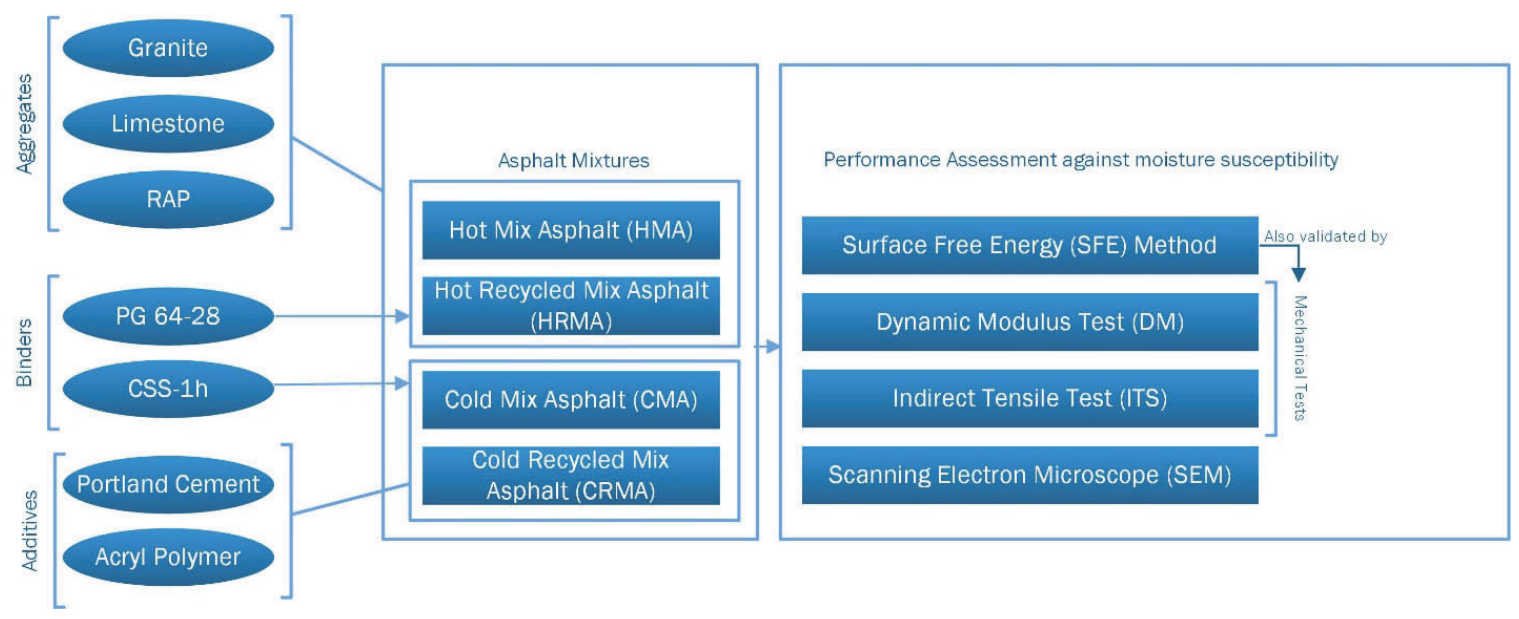

Figure 1: Chart of subjects of this study.

\section{Literature review}

Estakhri et al. [13] found that compared to the conventional hot mix asphalt (HMA) mixtures, binder-aggregate adhesion bond was atenuated in WMA mixtures. This conclusion was based on conducting SFE tests on the WMA samples with different combinations of aggregate, binder, and WMA additive. Arabani et al. [14] made use of the SFE method and estimated the effect of using WMA additives such as Sasobit and Asphamin along with the antistripping agents on the moisture susceptibility of WMA mixture. It was discovered that the use of WMA additives increased the acidity and decreased the base component of modified binder. Since their used aggregate had acidic property, it atenuated the adhesion bond and therefore decreased the moisture resistance. On the other side, adding the antistripping agent (Zycosoil) increased their adhesion energy in wet condition and made WMA mixture more resistant against moisture. Ghabchi et al. [15] used another WMA additive named Evotherm and applied the SFE method to evaluate the moisture susceptibility of different samples in this study. Measured SFE parameters and works of adhesion demonstrated improved resistance of modified- WMA mixtures against moisture damage. Moghadas nejad et.al [16] modified two types of aggregates by hydrated lime treatment and investigated the moisture susceptibility of constructed HMAs by SFE test. It was concluded that hydrated lime-modified samples enjoyed lower acidity and higher base component. Also, the dry/wet ratio of free energy (compatibility ratio) reduced considerably for hydrated lime modified samples. All of these changes implied a more resistant mixture against moisture damage. In another study by Arabani et al. [17] the moisture susceptibility of liquid antistripping additive (LAA) - modified HMA was evaluated by the SFE method and validated by a mechanical test (dynamic modulus test). It was understood that the total SFE of LAA-modified asphalt increased because of LAA modification. Increase in total SFE caused to weakening of adhesion bond which was compatible with achieved results by the performed dynamic modulus test. Shafabakhsh and Faramarzi $[18,19]$ also evaluated adhesion bond between the binder and aggregates in sulfur extended asphalt mixture by the SFE method. In their study, they used nanotechnology Zycotherm (NZ) to improve this bond which was an antistripping additive. Their findings showed that adding NZ successfully compensated the deteriorated adhesion due to using sulfur and the SFE test results were consistent with the common mechanical tests in prediction of moisture susceptibility. Seref Oruc et al. [20] found that mechanical properties of emulsified asphalt mixtures have significantly improved with Portland cement addition. This experimental study suggested that cement modified asphalt emulsion mixtures might be an alternate way of a structural layer material in pavement. Also emulsified asphalt mixtures have environmental, economical, and logistical advantages over hot mixtures. 


\section{EXPERIMENTAL PROCEDURE}

\section{Asphalt binder, aggregates and additives}

7 he virgin asphalt binder, PG 64-22 was used in this investigation to make HMAs and HRMAs. Its physical properties are summarized in Tab. 1. Type CSS-1h of the cationic asphalt emulsion, with properties shown in Tab. 2, was used to make CMAs and CRMAs. Crushed aggregates were used in this study which had desired mechanical properties such as sufficient strength, toughness, and hardness provided higher stability. Gradation of virgin aggregates is shown in Tab. 3. The gradation of RAP material, shown in Tab. 4, was chosen according to the gradation of coarse RAP determined by ARRA [3]. Since SFE test highly depends on aggregates chemical compositions, chemical compositions of used virgin aggregates measured by Electron Microprobe Analyzer are presented in Tab. 5. As shown in this table, PH of both aggregates is slightly more than 7 , and then they are considered basic. The origin of all the aggregates is Eshtehard Industrial Park and they are displayed in Fig. 2.

\begin{tabular}{ccccccccc}
\hline Properties & $\begin{array}{c}\text { PG } \\
\text { grade }\end{array}$ & $\begin{array}{c}\text { Purity } \\
\text { grade }\end{array}$ & $\begin{array}{c}\text { Flash } \\
\text { point }\end{array}$ & $\begin{array}{c}\text { Softening } \\
\text { point }\end{array}$ & $\begin{array}{c}\text { Penetration } \\
\text { Grade at } 25^{\circ} \mathrm{C}\end{array}$ & $\begin{array}{c}\text { Ductility at } \\
25^{\circ} \mathrm{C}\end{array}$ & $\begin{array}{c}\text { Viscosity } \\
\text { at } 135^{\circ} \mathrm{C}\end{array}$ & Density \\
Unit & - & $(\%)$ & $\left({ }^{\circ} \mathrm{C}\right)$ & $\left({ }^{\circ} \mathrm{C}\right)$ & $(\mathrm{mm} / 10)$ & $(\mathrm{cm})$ & $(\mathrm{mPa}) \mathrm{s})$ & - \\
Value & $64-22$ & 99 & 262 & 54 & 67 & 104 & 349 & 1.03 \\
\hline
\end{tabular}

Table 1: Physical properties of asphalt binder.

\begin{tabular}{cccccccc}
\hline Properties & $\begin{array}{c}\text { Residue by } \\
\text { distillation }\end{array}$ & $\begin{array}{c}\text { Saybolt furol } \\
\text { viscosity at } 25^{\circ} \mathrm{C}\end{array}$ & $\begin{array}{c}\text { Penetration } \\
\text { at } 25^{\circ} \mathrm{C}\end{array}$ & $\begin{array}{c}\text { Ductility, } 25^{\circ} \mathrm{C}, \\
5 \mathrm{~cm} / \mathrm{min}, \mathrm{cm}\end{array}$ & $\begin{array}{c}\text { Settlement, } \\
5 \text { day, }\end{array}$ & PH & Flammability \\
Unit & $\%$ & $\mathrm{sec}$ & $0.1 \mathrm{~mm}$ & $\mathrm{~cm}$ & $\%$ & - & - \\
Values & 63.0 & 34 & 70 & 84 & 0.1 & 5.37 & Non-flammable \\
\hline
\end{tabular}

Table 2: CSS-1h emulsion characteristics.

\begin{tabular}{ccccccc}
\hline Sieve $(\mathrm{mm})$ & $3 / 4 "$ & $1 / 2 "$ & $\# 4$ & $\# 6$ & $\# 50$ & $\# 200$ \\
Lower-upper limits & 100 & $90-100$ & $44-74$ & $28-58$ & $5-11$ & $2-10$ \\
Passing $(\%)$ & 100 & 92 & 53 & 55 & 12 & 6 \\
\hline
\end{tabular}

Table 3: Gradation of virgin aggregates.

\begin{tabular}{cccccc}
\hline Sieve Size & $11 / 4 "$ & $3 / 4^{\prime \prime}$ & $\# 4$ & $\# 30$ & $\# 200$ \\
Lower-upper limits & 100 & $93-97$ & $48-52$ & $8-12$ & $0.5-2$ \\
Passing (\%) & 100 & 91 & 50 & 10 & 2 \\
\hline
\end{tabular}

Table 4: Gradation of used RAP aggregates.

\begin{tabular}{ccc}
\hline Properties & Limestone & Granite \\
$\mathrm{PH}$ & 7.6 & 7.2 \\
$\mathrm{SiO}_{2}(\%)$ & 4.1 & 69.9 \\
$\mathrm{R}_{2} \mathrm{O}_{3}(\%)$ & 18.2 & 16.1 \\
$\mathrm{Al}_{2} \mathrm{O}_{3}(\%)$ & 1.2 & 14.9 \\
$\mathrm{Fe}_{2} \mathrm{O}_{3}(\%)$ & 0.4 & 1.6 \\
$\mathrm{MgO}(\%)$ & 11.7 & 0.9 \\
$\mathrm{CaO}(\%)$ & 51.1 & 2.2 \\
\hline
\end{tabular}

Table 5: Chemical Composition of used virgin aggregates measured by Electron Microprobe Analyzer. 


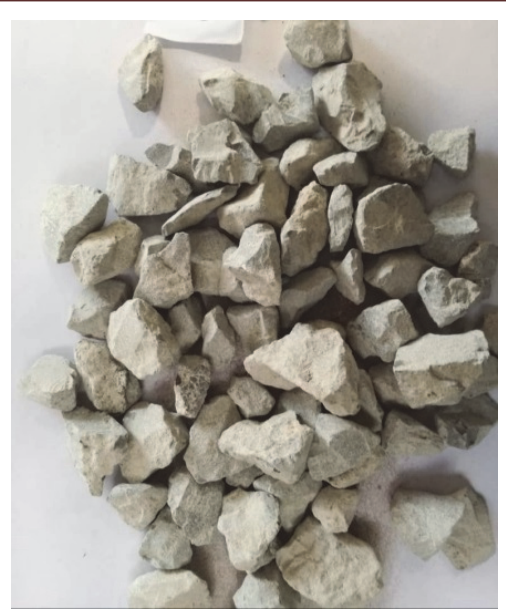

a)

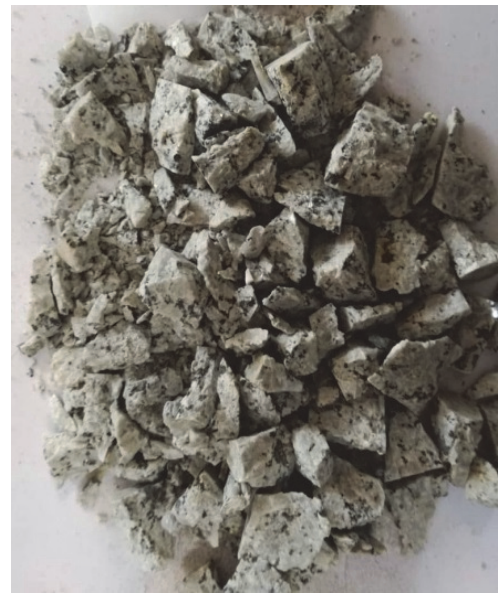

b)

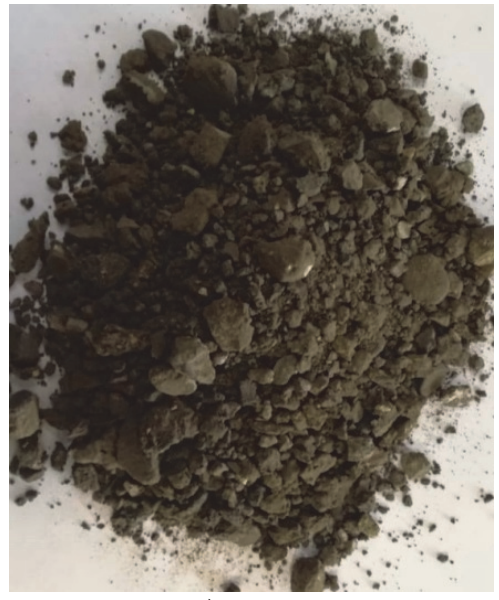

c)

Figure 2: Aggregates; a) Limestone b) Granite c) RAP

Properties of acrylic polymer (AP) are shown at Tab. 6. Because this material was in liquid form at environment temperatures, it could properly be mixed with cold mix asphalt. Although this product was initially designed as a PC concrete additive, due to using cationic emulsion (CSS-1h) and cement in the studied CRMA it was expected to make improvement on this mixture, too. According to the information provided by the producer company, this additive was supposed to significantly improve adhesion, cohesion, tensile, compressive, and flexural strengths of materials. Other company-reported features of this additive are as follow:

- Not re-emulsify when exposed to water.

- Good chemical and UV resistance.

- Improving freeze/thaw stability of Portland cement-based materials.

Another additive used in this study was Portland cement. According to ARRA [3] properties of PC additive used in CRMA should be consistent with AASHTO's specifications for PC Type I or Type II (AASHTO M 85, AASHTO M 240) [2]. Applied PC was type one with chemical properties shown in Tab. 7.

\begin{tabular}{ccc}
\hline Property & Unit & Value \\
Density & $\mathrm{g} \mathrm{mL}^{-1}$ & 1.04 \\
Solid content by volume & $\%$ & 28 \\
color & - & Milky white \\
Molar Volume $\mathrm{V}_{\mathrm{m}}$ & $\mathrm{mL} \mathrm{mol}^{-1}$ & 103.1 \\
Van-der-Waals Volume & $\mathrm{mL} \mathrm{mol}^{-1}$ & 76.76 \\
Solubility Parameter & $\mathrm{MPa}^{1 / 2}$ & 18.0 \\
Molar Cohesive Energy & $\mathrm{J} \mathrm{mol}^{-1}$ & 38600 \\
\hline
\end{tabular}

Table 6: Physical properties of used acryl polymer.

\begin{tabular}{cc}
\hline Content & $\%$ (By weight $)$ \\
$\mathrm{SiO}_{2}$ & 20.65 \\
$\mathrm{Al}_{2} \mathrm{O}_{3}$ & 6.33 \\
$\mathrm{Fe}_{2} \mathrm{O}_{3}$ & 3.01 \\
$\mathrm{CaO}$ & 61.44 \\
$\mathrm{MgO}$ & 3.11 \\
$\mathrm{~S} \mathrm{O}_{3}$ & 2.89 \\
Loss on Ignition & 1.35 \\
$\mathrm{Na}_{2} \mathrm{O}$ & 0.19 \\
$\mathrm{~K}_{2} \mathrm{O}$ & 1.03 \\
Total & 100 \\
\hline
\end{tabular}

Table 7: Chemical properties of the Portland cement. 


\section{Mix Design of HMA Specimens}

The Superpave mix design [2] was followed in determination of the optimum binder content (OBC). Hot mix asphalt samples were also produced according to this mix design with an air void content of $7.0 \%$.

\section{Mix Design of Cold Recycled Mix Asphalt (CRMA) Specimens}

At first, the RAP was thoroughly mixed with an optimum water contents (OWC). The OWC was $8.5 \%, 8.0 \%$ and $2.5 \%$ for limestone, granite, and RAP aggregates, respectively which was determined by conducting proctor test on the aggregates. The aggregates, after being mixed with water, were mixed with asphalt emulsion. In the case where PC was the only additive in PC-CRMA, it was added and mixed with wet aggregates for one minute before addition of emulsion. On the other hand, when both PC and AP were used as the additives in PC-AP-CRMA, first AP was mixed with aggregates and then PC was added to the wet aggregates. Finally, asphalt emulsion was added to the mixture and blended. The optimum emulsion contents of CMA/CRMA made with limestone, granite and RAP were determined to be 7.0\%, $6.5 \%$ and $3.5 \%$, respectively. Also, the optimum contents were found to be $1.5 \%$ and $1 \%$ as the optimum acrylic polymer and Portland cement contents by superpave method, respectively by conducting indirect tensile strength test (IDT) on conditioned and unconditioned specimens made with different emulsion, AP and PC combinations and contents (AASHTO T283 [2]). Another criterion considered in determining optimum water and polymer contents was that they should be high enough to make the asphalt emulsion coat all aggregates [3]. For the coating test hand mixing using a spoon and bowl was preferred over mechanical mixing since coating and workability could be easily observed. In production of all CRMAs, either modified or unmodified, mixing time did not exceed 60 seconds in each step of mixing process as per ARRA standard [3]. One specimen was mixed at a time. The compaction of CRMAs was done in 30 gyrations using a Superpave gyratory compactor (SGC) at a stress of $600 \mathrm{KPa}$ and angle of $1.25^{\circ}$ according to AASHTO T 312 [2]. In this case, air voids were only recorded, and recycling agent content were not adjusted to meet air void content. After compaction, paper disks were removed. Also, were remolded and put in a container. Specimens were cured at $60^{\circ} \mathrm{C}$ for $24 \mathrm{~h}$, and then cured in ambient temperature for another $24 \mathrm{~h}$. Sample preparation procedure is displayed in Fig. 3.

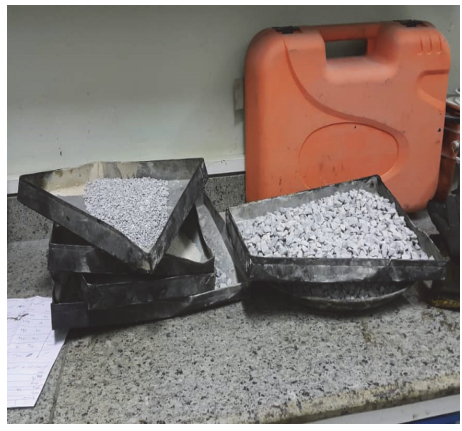

a)

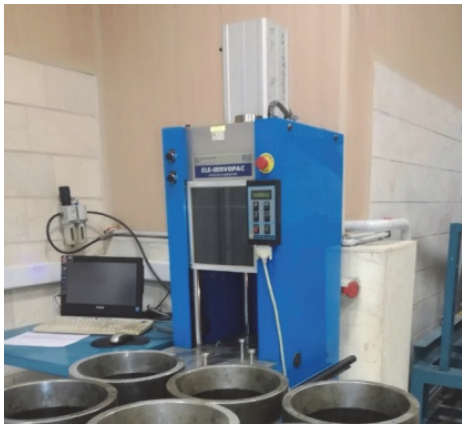

c)

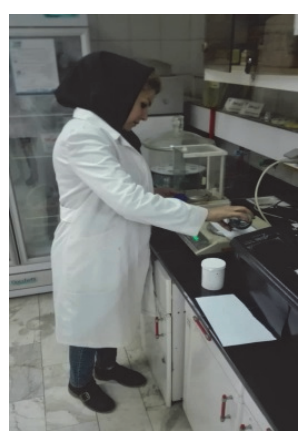

b)

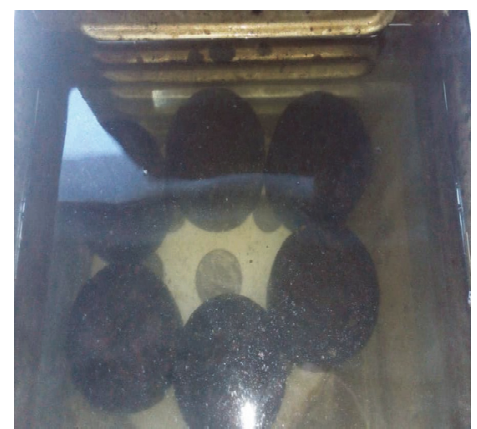

d)

Figure 3: Sample preparation; a) Aggregates b) Optimum contents of Emulsion, AP and PC c) Compaction using SGC machine d) Cured specimens. 
Dynamic Modulus Test

The purpose of conducting dynamic modulus test was to calculate the parameter $\mathrm{P}$ which is one of the parameters in the SFE method for prediction of moisture damage. The results of this test were also used as a validation of another parameter $(\mathrm{K})$. In the SFE method the parameter $(\mathrm{P})$ is called "aggregate surface area (\%) in contact with water", and the parameter $(\mathrm{K})$ is "dry/wet ratio of dynamic modulus values". For every mixture, six specimens were prepared including three specimens for each unconditioned and conditioned modes. The difference between unconditioned and conditioned specimens is in that the unconditioned specimens were not under moisture conditioning before test while the conditioned specimens were treated in accordance with the AASHTO T283 [2]. They were immersed in water (up to 55-80\% saturation Level), then freezed at $-18^{\circ} \mathrm{C}$ for 16 hours; and finally placed in a water bath at $60^{\circ} \mathrm{C}$ for 24 hours. The dynamic modulus along with the phase angle is the linear viscoelastic properties of the asphalt mixture. This property describes the correlation between stress and strain for a linear Viscoelastic substance under sinusoidal loading. In this test, uniaxial compressive load is exerted to the cylindrical specimen in cyclic sinusoidal mode. The property, as demonstrated in Eqn. (1), could be calculated by dividing the maximum applied stress to its corresponding recorded strain in each cycle of loading which is called dynamic modulus in case the absolute values are considered. The cyclic loading in our study was conducted at a frequency of $1 \mathrm{~Hz}$ and magnitude of $200 \mathrm{MPa}$ while the temperature was kept constant at $25^{\circ} \mathrm{C}$. Because the test was performed at the constant stress mode, the dynamic modulus property could be calculated by measuring the maximum recorded strain in each cycle.

$$
\left|E^{*}\right|=\frac{\sigma_{\max }}{\varepsilon_{\max }}
$$

where $\sigma_{\max }=200 \mathrm{MPa}$; and $\varepsilon_{\max }$ is the maximum recorded strain for each cycle.

So, the wet/dry ratio of the dynamic modulus could be computed by the following relationship for each cycle:

$$
\mathrm{K}=\frac{\left|\mathrm{E}^{*}\right|_{\text {wet }}}{\left|\mathrm{E}^{*}\right|_{\text {dry }}}
$$

The higher this ratio (parameter $\mathrm{K}$ ), the more resistant asphalt mixture against moisture damage.

\section{Surface Free Energy Test}

The SFE factors of binder and aggregates could be used in estimating healing, moisture susceptibility and fatigue life [21]. Cheng. [21] applied the equations introduced by Good et al. [22] to estimate adhesion work between bitumen and aggregates in dry and moist conditions. Surface free energy (SFE) for every material contains Lifshitz-van der Waals part, acid and base part. In other words, $\Gamma^{\mathrm{LW}}, \Gamma^{+}$and $\Gamma^{-}$. For each aggregate and bitumen, the total SFE could be achieved by Eqn. (3):

$$
\Gamma=\Gamma^{\mathrm{LW}}+\Gamma^{\mathrm{AB}}
$$

where $\Gamma$ is Total SFE parameter; $\Gamma^{\mathrm{LW}}$ is the Lifshitz-van der Waals parameter; and $\Gamma^{\mathrm{AB}}$ is acid-base parameter. The acidbase parameter can be rewritten in a new form constituting separate acid and base components (Eqn. (4))

$$
\Gamma^{\mathrm{AB}}=2\left(\Gamma^{+} \Gamma^{-}\right)^{0.5}
$$

where $\Gamma^{+}$is the acid factor of SFE; and $\Gamma^{-}$is the base factor of SFE.

The SFE of cohesion $\left(\Delta \mathrm{G}_{\mathrm{i}}^{\mathrm{c}}\right)$ is the required energy to separate a material from another in a unit area under the vacuum condition [23]. The parameter $\Delta G_{i}^{c}$ could be obtained by Eqn. (5):

$$
\Delta G_{\mathrm{i}}^{\mathrm{c}}=2 \Gamma_{\mathrm{i}}
$$


From the other point of view, the SFE of adhesion $\left(\Delta G^{\alpha}\right)$ is defined as the required energy to take two bonded material apart in a unit area of interconnection point, under the vacuum condition [12]. The parameter $\Delta G^{\alpha}$ could be computed by Eqn. (6):

$$
\Delta \mathrm{G}_{\mathrm{i}}^{\alpha} .=\Delta \mathrm{G}_{\mathrm{i}}^{\alpha \mathrm{LW}}+\Delta \mathrm{G}_{\mathrm{i}}^{\alpha \mathrm{AB}}=-2\left[\sqrt{\Gamma_{2}^{\mathrm{LW}} \Gamma_{1}^{\mathrm{LW}}}+\sqrt{\Gamma_{2}^{+} \Gamma_{1}^{-}}+\sqrt{\Gamma_{2}^{-} \Gamma_{1}^{+}}\right]
$$

where $\Delta \mathrm{G}_{\mathrm{i}}^{\alpha}=$ the SFE of adhesion; $\Delta \mathrm{G}_{\mathrm{i}}^{\alpha \mathrm{LW}}=$ the LW parameter of adhesion; $\Delta \mathrm{G}_{\mathrm{i}}^{\alpha \mathrm{AB}}=$ the acid-base parameter of adhesion; and $\Gamma^{\mathrm{LW}}, \Gamma^{-}$, and $\Gamma^{+}=$the SFE parameters (subscript 1 corresponds to binder; subscript 2 corresponds to aggregate).

It is necessary to also compute the SFE of adhesion between bitumen and aggregate with water to estimate the asphalt mixture behavior in moist condition. The following equation could be used to compute the SFE of adhesion between two connected materials, when there is a third material in the system [21]:

$$
\Delta \mathrm{G}_{123}^{\mathrm{abs}}=\gamma_{\mathrm{aw}}+\gamma_{\mathrm{bw}}-\gamma_{\mathrm{ab}}
$$

In Eqn. (7), indices 1, 2, and 3 could be replaced by aggregate, asphalt binder and water respectively; $\gamma_{\mathrm{ij}}$ is the adhesion bond between materials $i$ and $j$ and could be obtained using SFE values in the following equations:

$$
\begin{aligned}
& \gamma_{i j}=\gamma_{i j}^{\mathrm{LW}}+\gamma_{i j}^{\mathrm{AB}} \\
& \gamma_{\mathrm{ij}}^{\mathrm{LW}}=\left(\sqrt{\gamma_{\mathrm{i}}^{\mathrm{LW}}}-\sqrt{\gamma_{j}^{\mathrm{LW}}}\right)^{2} \\
& \gamma_{\mathrm{ij}}^{\mathrm{AB}}=2\left(\sqrt{\gamma_{i}^{+}}-\sqrt{\gamma_{j}^{+}}\right)\left(\sqrt{\gamma_{\mathrm{i}}^{-}}-\sqrt{\gamma_{j}^{-}}\right)
\end{aligned}
$$

Because this system (aggregate, asphalt binder and water) is unstable, aggregates tend to separate from asphalt binder and make a bond with water. This process releases energy and hence as a result the value of energy of adhesion will be negative. The more negative this value, the more instability in the system [22].

Dry/Wet ratio of adhesion energy is a convenient parameter to estimate resistance against moisture damage. This parameter which is called compatibility ratio (CF) could be achieved by using Eqns. (6) and (7), as it is displayed in the following equation:

$$
\mathrm{CF}=\frac{\Delta \mathrm{G}_{\mathrm{i}}^{\mathrm{a}}}{\Delta \mathrm{G}_{123}^{\text {abs }}}
$$

The most common tests for measuring SFE parameters of aggregate and binder are Universal Sorption Device (USD) and Wilhelmy Plate (WP) which were first introduced by Bhasin et al. [24] and Hefer et al. [25], respectively. The SFE parameters of a solid surface could be measured by using an intermediate material called probe; because direct measurement is impossible. In this approach, the function of adhesion between the probe substance (known SFE parameters) and solid surface (unknown SFE parameters) should be evaluated. Because aggregates enjoy high SFE values, adsorption method could be a proper procedure to evaluate the function of adhesion between aggregates and probe agent. This procedure is based on the correlation between the vapor pressure and magnitude of absorbed vapor by the aggregates surface. In order to use Eqn. (12) for calculating the SFE parameters of each aggregate, since there is a linear relationship between the SFE components of aggregate and the adhesion work, three different probe materials are necessary. As a result, a linear system of three equations and three unknowns will be obtained which should be solved to obtain three SFE components of each aggregate.

$$
\mathrm{W}_{\mathrm{S}, \mathrm{V}}^{\mathrm{a}}=\pi_{\mathrm{e}}+2 \Gamma_{\mathrm{V}}^{\mathrm{total}}=-2\left[\left(\Gamma_{\mathrm{S}}^{\mathrm{LW}} \Gamma_{1}^{\mathrm{LW}}\right)+\left(\Gamma_{\mathrm{S}}^{+} \Gamma_{1}^{-}\right)+\left(\Gamma_{\mathrm{S}}^{-} \Gamma_{1}^{+}\right)\right]
$$


where, $\mathrm{S}$ and $\mathrm{V}$ refer to the aggregates and vapor probe, respectively; $\mathrm{W}_{\mathrm{S}, \mathrm{V}}^{\mathrm{a}}$ is work of adhesion; $\Gamma_{\mathrm{V}}^{\text {total }}$ is probe's total surface energy; and $\pi_{\mathrm{e}}$ is the equilibrium spreading pressure of the probe over the stone grains surface. In USD method, the gas-adsorption parameters of probes should be applied to calculate the SFE parameters of each aggregate. The USD device is formed of a balance system, temperature controller, computer, vacuum device and its regulator, pressure gauge, vacuum dissector, and a probe container. The aggregates were dried and sieved (between $4.75 \mathrm{~mm}$ and $2.36 \mathrm{~mm}$ ). Grains sizes were evaluated by the grain holder used in the USD form of aluminum mesh. The amount grain stones that remained on the 2.36- $\mathrm{mm}$ sieve, are about Nearly $40 \mathrm{~g}$ (dust), which was eliminated with neat water. Then the grain stones were washed to be prepared for the test. In the washing process grains were washed with: 1) distilled water, 2) methanol, 3) hexane, and 4) methanol again. The washing process was continued for four-hour oven drying. Then the aggregates were kept awhile in the room temperature, and then transferred to the aluminum container of USD test device. Three chosen probe materials in this research were n-hexane, MPK, and water, which are nonpolar, monopolar and bipolar materials, respectively. Their SFE specifications are calculated and summarized in Tab. 8. The pressure in which these probe materials are spread over the stone grains could be computed by Eqn. (13):

$$
\pi_{\mathrm{e}}=\frac{\mathrm{RT}}{\mathrm{MA}} \int_{0}^{\mathrm{p}_{\mathrm{n}}} \frac{\mathrm{n}}{\mathrm{p}} \mathrm{dp}
$$

where $\mathrm{R}=$ the universal gas coefficient; $\mathrm{T}=$ the testing temperature; $\mathrm{M}=$ the probe material molecular weight; $\mathrm{n}=$ mass of probe material that penetrates in grain's unit mass (at probe pressure p); and A = the specific surface area of grain. The grains specific surface area could be computed using the following equation which is called BET equation:

$$
\mathrm{A}=\left(\frac{\mathrm{n}_{\mathrm{m}} \cdot \mathrm{N} 0}{\mathrm{M}}\right) \alpha
$$

where, $\mathrm{N} 0=$ number of Avogadro; $\mathrm{n}_{\mathrm{m}}=$ capacity of grain stone monolayer; and $\alpha=$ projected area of one molecule. Monolayer capacity is described as the quantity of molecules needed for covering one layer of grain surface. This parameter could be determined by obtaining the gradient (S) and the y-intercept (I) of the best fit line between $\mathrm{p} / \mathrm{n}\left(\mathrm{p}_{0}-\mathrm{p}\right)$ and $\mathrm{p} / \mathrm{p}_{0}$ values (obtained by least square method), in which $\mathrm{p}=$ partial pressure of the probe vapor; $\mathrm{p}_{0}=$ saturation pressure of the probe vapor; and $\mathrm{n}=$ mass of the absorbed vapor to the unit area of stone grains. For the partial pressures in the range of 0 to 0.35 , the best fit line is accurate and the BET equation could be used, so $\mathrm{n}_{\mathrm{m}}$ can be calculated from:

$$
\mathrm{n}_{\mathrm{m}}=\frac{1}{\mathrm{~S}+\mathrm{I}}
$$

Using the Young-Dupre equation, the following equation was made between the Gibbs adhesion bond $\left(\Delta \mathrm{G}_{\mathrm{L}, \mathrm{S}}^{\mathrm{a}}\right)$, the function of adhesion $\left(\mathrm{W}_{\mathrm{L}, \mathrm{S}}^{\mathrm{a}}\right)$, the contact angle $(\theta)$ related to a probe material $(\mathrm{L})$, which is in touch with a solid $(\mathrm{S})$, and the SFE factors of solid and liquid materials:

$$
\Delta \mathrm{G}_{\mathrm{L}, \mathrm{S}}^{\mathrm{a}}=\mathrm{W}_{\mathrm{L}, \mathrm{S}}^{\mathrm{a}}=\Gamma_{\mathrm{L}}^{\mathrm{total}}(1+\cos \theta)=2\left(\sqrt{\Gamma_{\mathrm{S}}^{\mathrm{LW}} \Gamma_{1}^{\mathrm{LW}}}+\sqrt{\Gamma_{\mathrm{S}}^{+} \Gamma_{1}^{-}}+\sqrt{\Gamma_{\mathrm{S}}^{-} \Gamma_{1}^{+}}\right)
$$

By using Eqn. (16) the SFE factors of bitumen was obtained by measuring contact angles. Variables of this relationship include in solid (S) which represents the bitumen and liquid $(\mathrm{L})$ which represents the probe materials that have distinguished SFE factors (Tab. 9). By putting the square root of unknown SFE parameters of bitumen with $\mathrm{x}_{1}, \mathrm{x}_{2}$, and $\mathrm{x}_{3}$, Eqn. (16) could be rewritten as:

$$
\Gamma_{\mathrm{L}}^{\mathrm{total}}(1+\cos \theta)=2\left(\mathrm{x}_{1} \cdot \sqrt{\Gamma_{1}^{\mathrm{LW}}}+\mathrm{x}_{2} \sqrt{\Gamma_{1}^{-}}+\mathrm{x}_{3} \sqrt{\Gamma_{1}^{+}}\right) \mathrm{s}
$$


By putting the SFE factors of probe material and the achieved value of contact angle from the Wilhelmy plate test in Eqn. (17), it will be in the same form of the Eqn. (12) which was used to compute the SFE factors of aggregates. By writing the force equilibrium between the ordinary weight of plate (dry weighting) and the weight of plate when it is half submerged in probe substance, $\Delta \mathrm{F}$ would be a parameter in this equilibrium that is related to the surface energy of liquid, dimension of plate and contact angle. From this equilibrium, the contact angle between plate and probe liquid could be calculated by the following equation:

$$
\cos \theta=\frac{\Delta \mathrm{F}+\mathrm{V}_{\text {im }}\left(\varrho_{\mathrm{L}}-\varrho_{\text {air }} \cdot \mathrm{g}\right)}{\mathrm{P}_{\mathrm{t}} \Gamma_{\mathrm{L}}^{\text {total }}}
$$

where, $\mathrm{P}_{\mathrm{t}}=$ plate's perimeter covered by asphalt binder; $\Gamma_{\mathrm{L}}^{\mathrm{total}}=$ total SFE of the probe; $\theta=$ plate- probe Contact angle; $\mathrm{V}_{\mathrm{im}}=$ volume of immersed part of plate; $\varrho_{\mathrm{L}}=$ probe material density; $\varrho_{\text {air }}=$ density of air, and $\mathrm{g}=$ gravitational force.

Lifshitz-van der Waals $\left(\Gamma_{s}^{L W}\right)$, Lewis base $\left(\Gamma_{s}^{-}\right)$, and Lewis acid $\left(\Gamma_{s}^{+}\right)$are three unknown parameters in Eqn. (17) which could be solved in a three equation three unknown system of linear equations if three known probe materials are used. There were three reasons for choosing those three materials as probes: 1) They have various SFE characteristics, 2) they have high values of SFE factors, and 3) bitumen would not be dissolved in them. More discussion about the SFE method is out of scope of this research and could be discovered in references [24, 25].

\begin{tabular}{cccccc}
\hline Absorbate & $\Gamma^{\mathrm{LW}}$ & $\Gamma^{\mathrm{A}}$ & $\Gamma^{\mathrm{B}}$ & $\Gamma^{\mathrm{AB}}$ & $\Gamma^{\text {Total }}$ \\
water & 21.8 & 25.5 & 25.5 & 51 & 72.8 \\
n- hexane & 18.4 & 0 & 0 & 0 & 18.4 \\
Methyl propyl keton & 24.7 & 0 & 19.6 & 0 & 24.7 \\
\hline
\end{tabular}

Table 8: Surface Free Energies of Solvent for Aggregates $\left(\mathrm{erg} / \mathrm{cm}^{2}\right)$.

\begin{tabular}{cccccc}
\hline Absorbent & $\Gamma^{L W}$ & $\Gamma^{A}$ & $\Gamma^{B}$ & $\Gamma^{A B}$ & $\Gamma^{\text {Total }}$ \\
Water & 21.8 & 25.5 & 25.5 & 51 & 72.8 \\
Formamide & 39 & 2.28 & 39.6 & 19 & 58 \\
Glycerol & 34 & 3.92 & 57.4 & 30 & 64 \\
\hline
\end{tabular}

Table 9: Surface Free Energies of Solvent Liquids $\left(\mathrm{erg} / \mathrm{cm}^{2}\right)$.

\section{RESULTS}

$\mathrm{I}$ phenomenon originates in the high polarity of aggregates. Despite the bitumen enjoys a high value of Lifitz-van der Waal (36.28 and $17.88\left(\mathrm{erg} / \mathrm{cm}^{2}\right)$ ) for PG 64-28 and CSS-1h, respectively) that is the Nonpolar factors of SFE, while has a low value of polar (0.89 and 1.03(erg/ $\left.\mathrm{cm}^{2}\right)$ ) for PG 64-28 and CSS-1h, respectively). Low polarity character of bitumen makes it more sensitive with water, as the water is essentially a very polar material. All studied asphalt binders showed relatively low values of acid-base $\left(\Gamma^{\mathrm{AB}}\right)$ component that originates in the low values of acid and base components. As it is intelligible by the acid and base component values, studied virgin PG 64-28 and CSS-1h were acidic material while, PCmodified asphalts showed basic properties (4.41 and $1.13\left(\mathrm{erg} / \mathrm{cm}^{2}\right)$ ) for base and acid components, respectively). On the other hand, according to the Tab. 10, asphalt emulsion showed higher values of acid-base parameter when it was modified with additives. As shown in the Tab. 10, the highest measure for acid-base parameter was achieved for Cement and polymer modified-emulsion.

As presented in Tab. 10, the acid/base ratio for all modified and unmodified asphalt emulsion binders were lower than the PG 64-28 asphalt binder and it was more considerable when asphalt emulsion was modified with additives. The lowest 
acid/base ratio was resulted when asphalt emulsion was only modified with PC. Normally, it is difficult to form an adhesion bond between asphalt binder and aggregates as asphalt binder is an acidic material while aggregates are basic, so it could be very advantageous if the acid component of binder be reduced and, on the other hand, the base and the Lifitzvan der Waal components be increased [27]. This ideal condition was satisfied when asphalt emulsion was modified with PC that is a cationic additive and has base property. Increasing base component of asphalt binder is the mechanism that causes PC to improve adhesion bond between aggregates and bitumen. As it is presented in Tab. 10, the Lifitz-van der Waal component of CSS-1H asphalt emulsion was less than PG 64-28 asphalt binder, on the other hand, this parameter was found much lower when asphalt emulsion was modified with PC. So, when the binder and aggregates are initially blended, acid-base component and Lifitz-van der Waal component of PC-modified emulsions are respectively more and less effective in the aggregate-binder bond formation in comparison virgin PG 64-28 and CSS-1h emulsion [28]. It could be seen in Tab. 10 that both of acid-base $\left(\Gamma^{\mathrm{AB}}\right)$ and Nonpolar component $\left(\Gamma^{\mathrm{LW}}\right)$ of PC- modified asphalt emulsion increased when AP was added as the second additive. Data provided in this section characterized asphalt binders SFE components, however, aggregates SFE components and finally SFE of aggregates-asphalt binder system are needed to judge about effect of applied additives on aggregate-asphalt binder adhesion.

\begin{tabular}{|c|c|c|c|c|}
\hline Asphalt - binder & PG 64-28 & $\begin{array}{l}\text { CSS-1H } \\
\text { Emulsion }\end{array}$ & $\begin{array}{c}\text { Cement } \\
\text { modified- emulsion }\end{array}$ & $\begin{array}{c}\text { Cement and } \\
\text { polymer } \\
\text { modified- emulsion }\end{array}$ \\
\hline Contact angle $\left(^{\circ}\right)$ with water & 76.88 & 65.42 & 69.4 & 68.61 \\
\hline Contact angle $\left(^{\circ}\right)$ with glycerol & 85 & 82.12 & 86.89 & 84.31 \\
\hline Contact angle $\left(^{\circ}\right)$ with formamide & 78 & 72.56 & 79.43 & 82.22 \\
\hline Total surface free energy, $\Gamma\left(\mathrm{erg} / \mathrm{cm}^{2}\right)$ & 37.17 & 18.91 & 10.08 & 10.88 \\
\hline Lifitz-van der Waal component, $\Gamma^{\mathrm{LW}}\left(\mathrm{erg} / \mathrm{cm}^{2}\right)$ & 36.28 & 17.88 & 5.62 & 6.29 \\
\hline Acid-base component, $\Gamma^{\mathrm{AB}}\left(\mathrm{erg} / \mathrm{cm}^{2}\right)$ & 0.89 & 1.03 & 4.46 & 4.59 \\
\hline Acidic component, $\Gamma^{+}\left(\mathrm{erg} / \mathrm{cm}^{2}\right)$ & 1.23 & 1.07 & 1.13 & 1.34 \\
\hline Basic component, $\Gamma^{-}\left(\mathrm{erg} / \mathrm{cm}^{2}\right)$ & 0.16 & 0.25 & 4.41 & 3.93 \\
\hline ratio between acid-to-base & 7.69 & 4.28 & 0.26 & 0.34 \\
\hline
\end{tabular}

Table 10: Surface Free Energy Components of used binders.

\section{SFE test- Aggregates}

In this study, the USD method was used to measure the SFE values of aggregates. Tab. 11 shows different SFE components of all studied aggregates (limestone, granite and RAP). As shown limestone and RAP had the highest (130.98 $\mathrm{erg} / \mathrm{cm}^{2}$ ) and lowest $\left(43.85 \mathrm{erg} / \mathrm{cm}^{2}\right.$ ) total surface free energy, respectively. The acid- base components of SFE followed this sequence and was the highest for limestone aggregates $\left(80.83 \mathrm{erg} / \mathrm{cm}^{2}\right)$ and lowest for RAP aggregates (18.68 erg/ $\left.\mathrm{cm}^{2}\right)$. On the other hand, Lifitz-van der Waal that is a nonpolar component, was the highest for granite aggregates $(57.3$ $\mathrm{erg} / \mathrm{cm}^{2}$ ) and lowest for RAP $\left(45.17 \mathrm{erg} / \mathrm{cm}^{2}\right.$ ). Considering the effects of higher $\Gamma^{\mathrm{LW}}$ and lower $\Gamma^{\mathrm{AB}}$ (higher polarity) in improvement of bond between binder and aggregates RAP material showed the lowest $\Gamma^{\mathrm{LW}}$ and $\Gamma^{\mathrm{AB}}$ which shows its higher potential for stripping and moisture susceptibility in comparison with virgin aggregates like limestone and granite.

\begin{tabular}{ccccccc}
\hline $\begin{array}{c}\text { Type of } \\
\text { aggregate }\end{array}$ & $\begin{array}{c}\text { 1)Acid } \\
\text { component }\end{array}$ & $\begin{array}{c}\text { 2)Base } \\
\text { component }\end{array}$ & $\begin{array}{c}\text { 3)Acid-base } \\
\text { component }\end{array}$ & $\begin{array}{c}\text { 4)Lifitz-van der Waal } \\
\text { component }\end{array}$ & $\begin{array}{c}\text { 5)Total } \\
\text { surface free energy }\end{array}$ & $\begin{array}{c}\text { 6)ratio between } \\
\text { acid-to-base }\end{array}$ \\
Limestone & 6.89 & 237.09 & 80.83 & 50.15 & 130.98 & 0.29 \\
Granite & 0.34 & 478 & 25.5 & 57.3 & 82.8 & 0.0007 \\
RAP & 18.98 & 244.08 & 18.68 & 45.17 & 43.85 & 0.045 \\
\hline
\end{tabular}

Table 11: Surface Free Energy Components of Aggregates $\left(\mathrm{erg} / \mathrm{cm}^{2}\right)$. 
SFE test-Adhesion bonds

When the SFE parameters of asphalt binders and aggregates are measured, it's possible to calculate the adhesion bond between binders and aggregates in dry and moist conditions by Eqn. 6 and Eqn. 7 respectively. The more the SFE amounts, the stronger bonds. The positive amount of "free energy of adhesion" means that fundamental materials will to stay bonded, and the more the SFE amounts, the stronger bonds; while the negative amounts of "free energy of adhesion" is equivalent with an unstable system and an attitude in the materials to be taken apart from each other. Since, the bitumen has lower amounts of SFE compared to the water, water is more able to wet aggregate surface in comparison with bitumen. It means that bitumen takes aggregate surface apart and water will be replaced, so, the more stable wateraggregate system will be formed [29].

As it is shown in Tab. 12 and Fig. 4, granite made the most powerful bond with different binders in absence of water, while RAP showed the weakest bond with binders in dry condition. On the other hand, limestone aggregates showed the highest asphalt binder- aggregates adhesion due to higher "free energy of adhesion" values in moist condition. On the other hand, granite made the weakest bond in wet condition. It could be explained by the free energy of adhesion in the water- granite system which had a greater negative magnitude in comparison with the water- limestone system and RAP. It implies that granite more than RAP, and RAP more than limestone were hydrophobic and moisture susceptible. As it could be comprehended from the Tab. 12, the PC modified asphalt emulsion showed "free energy of adhesion" (81.58, 99.80 and $87.15 \mathrm{erg} / \mathrm{cm}^{2}$ for limestone, granite and RAP, respectively) lower than the PG 64-28 (121.56, 161.52 and $\left.119.10 \mathrm{erg} / \mathrm{cm}^{2}\right)$ and higher than CSS-1h asphalt emulsion $\left(75.75,84.83\right.$ and $\left.73.52 \mathrm{erg} / \mathrm{cm}^{2}\right)$; It shows that adding PC improves adhesion between aggregates and asphalt emulsion, however, it has less adhesion than PG 64-28 because of different nature of PG asphalt binder and asphalt emulsions. Also, adding AP improved this adhesion in some extent (81.58, 99.80 and $\left.87.15 \mathrm{erg} / \mathrm{cm}^{2}\right)$. As it is shown in the Tab. 12 and Fig. 4, asphalt emulsion modified with PC and AP showed the least amount of free energy of adhesion in presence of water led to the highest surface energy of adhesion for both of limestone and granite aggregates (113.14 and 129.32 respectively); In contradict with the dry condition in which granite showed the best adhesion, as it is shown in the Tab. 12 and Fig. 4, the bond between aggregates and binders are more unstable in presence of water for the granite compared to RAP and limestone aggregates.

\begin{tabular}{|c|c|c|c|c|c|}
\hline $\begin{array}{l}\text { 1)Types } \\
\text { of } \\
\text { aggregate }\end{array}$ & $\begin{array}{l}\text { 2) Type of } \\
\text { asphalt mixture }\end{array}$ & $\begin{array}{l}\text { 3)Asphalt binder } \\
\text { - aggregate }\end{array}$ & $\begin{array}{l}\text { 4)Water- } \\
\text { aggregate }\end{array}$ & $\begin{array}{l}\text { 5)Asphalt binder-aggregate } \\
\text { in presence of water }\end{array}$ & 6) $\mathrm{CR}$ \\
\hline Limestone & HMA & 121.56 & 248.15 & -70.59 & 1.72 \\
\hline Limestone & CMA & 75.75 & 248.15 & -56.81 & 1.33 \\
\hline Limestone & PC- CMA & 77.34 & 248.15 & -52.80 & 1.46 \\
\hline Limestone & AP-PC-CMA & 81.58 & 248.15 & -55.03 & 1.48 \\
\hline Granite & HMA & 161.52 & 313.95 & -108.49 & 1.49 \\
\hline Granite & CMA & 84.83 & 313.95 & -81.24 & 1.04 \\
\hline Granite & PC- CMA & 93.23 & 313.95 & -85.06 & 1.10 \\
\hline Granite & AP-PC-CMA & 99.80 & 313.95 & -88.58 & 1.13 \\
\hline RAP & HRMA & 119.10 & 264.54 & -87.31 & 1.36 \\
\hline RAP & CRMA & 73.52 & 264.54 & -72.45 & 1.01 \\
\hline RAP & PC- CRMA & 83.38 & 264.54 & -66.28 & 1.26 \\
\hline RAP & AP-PC- CRMA & 87.15 & 264.54 & -68.34 & 1.28 \\
\hline
\end{tabular}

Table 12: Free Energy of Adhesion $\left(\mathrm{erg} / \mathrm{cm}^{2}\right)$. 


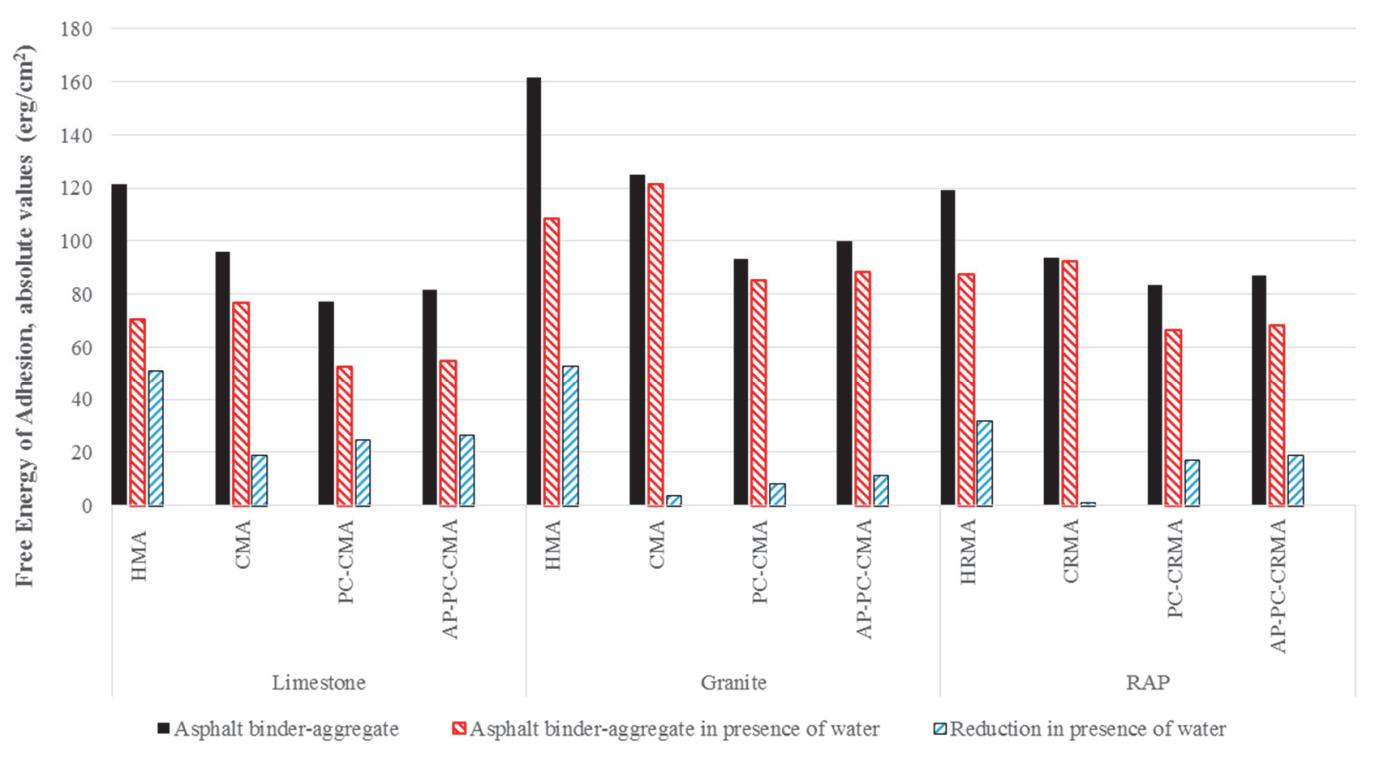

Figure 4: Free energy of adhesion between asphalt and aggregates with/without presence of water.

\section{SFE test- Selection of aggregates}

It is more desirable for a mixture to have high adhesion energy between the aggregate and the bitumen in dry condition and low released energy in moist condition. To notice these two factors, Dry/Wet ratio of adhesion energy is a convenient factor to estimate resistance of any mixture against moisture damage. This parameter is called compatibility ratio (CR). Since, in the moist condition energy is released from the system, its value $\Delta G_{123}^{\text {abs }}$ is negative, so in computation of compatibility ratio the absolute value would be used. Use of this ratio for estimating mixtures durability is so useful in mixture designing, because by measuring the SFE parameters of different bitumen and aggregates, it is possible to compute their various blend and recognize the best compatible combinations to be utilized [24].

In order to do such a computation for 12 different prepared binder samples, SFE specifications of 4 different bitumen as well as three used aggregates were applied from Tab. 10 and Tab. 11 respectively. As it is shown in Tab. 12, the amounts in column number 3, 4, 5 and 6 are computed using Eqn. 6, Eqn. 7 and Eqn. 11 respectively. Compatibility ratio (CR) is the major factor of this table for aggregate selection that could be computed using amounts of column number 3 and number 5. CR factor is the most reliable and complete criteria to estimate the durability of any asphaltic sample by SFE method. Based on calculated ratios, all of the samples had higher ratio with limestone in comparison with granite and RAP. It could be understood that limestone made a more resistant mixture against wet condition and could be chosen as the selected aggregate in mixture design. As it is illustrated in the Tab. 12, both PC and AP additives improved the CR and among these two additives effect of PC was more considerable. AP- modified asphalt emulsion resulted the greatest ratios between all three studied asphalt emulsions, therefore, could make the most compatible mixture. So, addition of AP made the PC- modified cold mix asphalts more resistant against moisture damage, as it was the main goal of using those additives in this study.

\section{Relationship between Surface Energy and Dynamic Modulus Methods}

The percentage of aggregate area in contact with water $(\mathrm{P})$ via number of cycles in DM test is illustrated by the diagrams in Figs. 5 to 7. Considering this parameter, limestone and granite resulted lower stripping in comparison with RAP due to better adhesion between aggregates and binders. As it's comprehensible by the HMA sample diagram in the Figs. 5 to 7 , this sample led the best application against stripping phenomenon (the least index P) followed by PC-AP- CMA, PC-CMA and CMA samples. So, cold mixtures were more vulnerable against stripping, although addition of PC and AP improved cold mixtures moisture susceptibility by increasing the index P parameter, specifically, when RAP was used, this improvement was more considerable. Modification of CRMA by PC and AP additives improved resistance of mixture against stripping and it was more considerable for granite than RAP. It's because of better adhesion of asphalt binder to virgin aggregates rather than RAP materials. Obtained results by calculating P factor proved that using PC and AP as additives was a successful method to reduce the moisture sensitivity of CMA, specifically, when the RAP was used. 


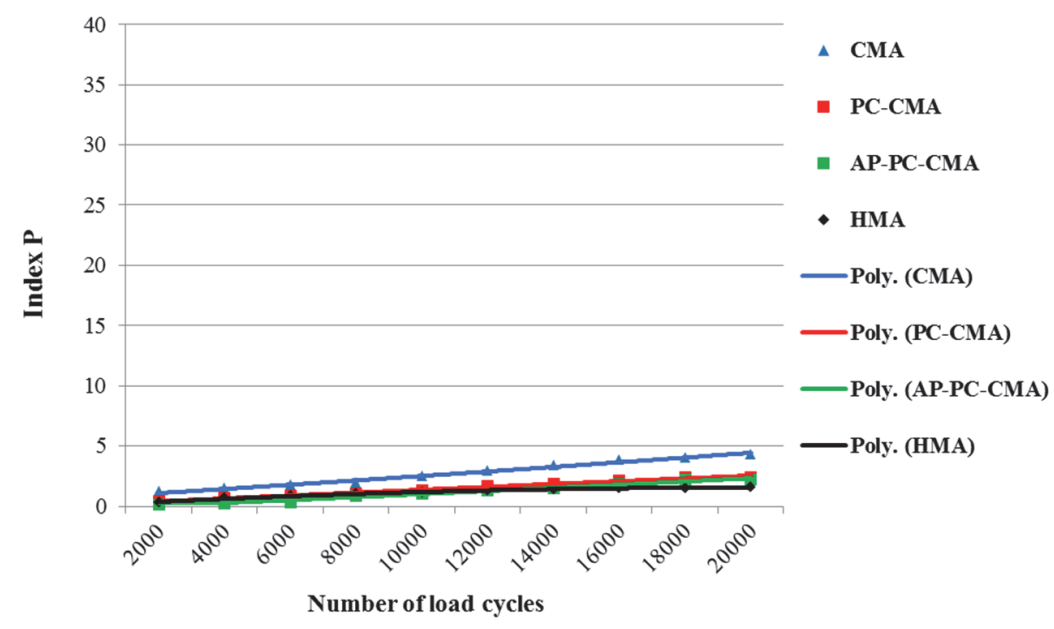

Figure 5: Aggregate surface area in contact with water (\%) versus number of cycles. (Limestone).

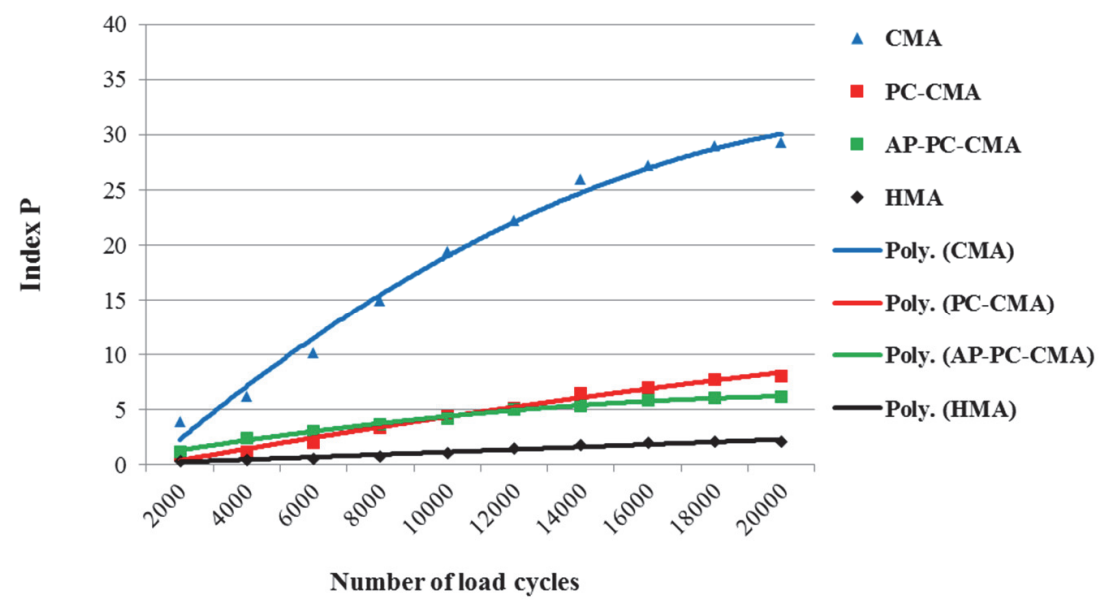

Figure 6: Aggregate surface area in contact with water (\%) versus number of cycles. (Granite).

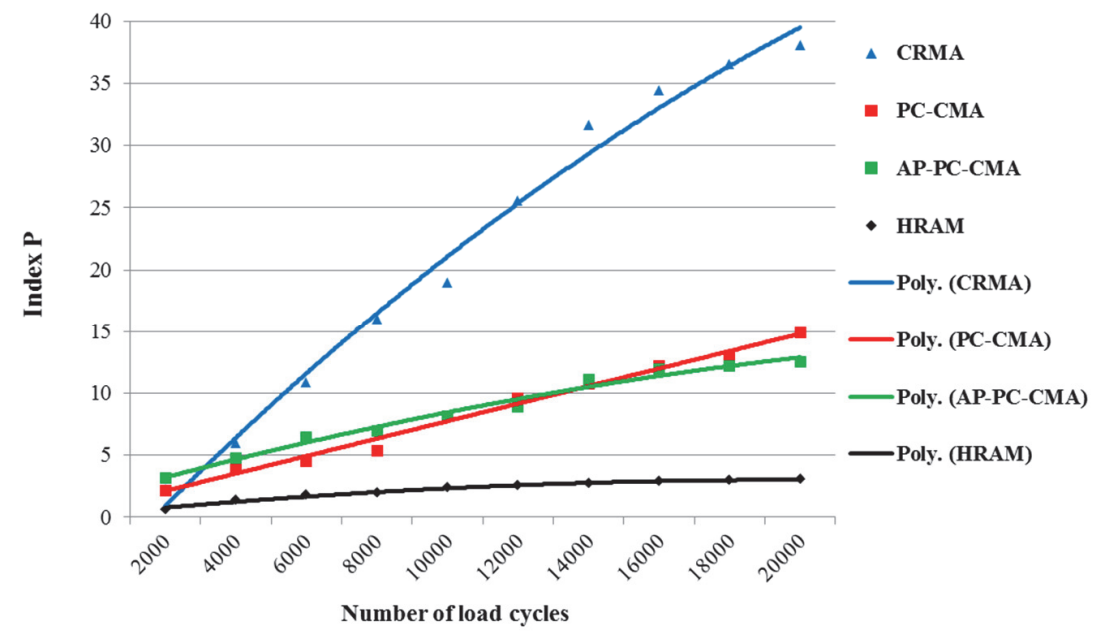

Figure 7: Aggregate surface area in contact with water (\%) versus number of cycles. (RAP).

\section{Mechanical moisture Susceptibility Tests}

In this study each sample was made in two groups of unconditioned and wet conditioned. Moisture susceptibility of asphalt mixtures could be measured by SFE method [19], like indirect tensile strength (ITS) and dynamic modulus (DM) 
tests. In general, wet conditioning conducted to lower ITS and dynamic modulus values in comparison with the unconditioned samples. To evaluate and compare the moisture susceptibility of different samples, wet/dry ratio was computed for the both of DM and ITS values. Such a lower strength was resulted in the weakened adhesion bond between bitumen and aggregates under the effect of wet conditioning and interaction between water and bitumen. In the Fig. 8, the tensile strength ratio (TSR) of all samples made of three types of aggregates (limestone, granite and RAP) is illustrated. It's Comprehensible from this figure that mixtures made by limestone had lower susceptibility against wet condition due to having higher TSR values in comparison with mixtures made by granite aggregates and RAP. This result is so closed to one that was obtained by the SFE method in the section "SFE test- Adhesion bonds"; Also, as it is shown in the Fig. 8, TSR ratio improved for cold mix asphalts modified with PC and AP additives specifically when using RAP and granite. The minimum TSR value for HMA and CMA are $80 \%$ and $70 \%$, respectively, to be considered resistant enough against moisture cracking [3]. As shown in Fig. 8, all modified CMAs passed this limit, successfully. To analyze and compare the effect of moist condition on the DM parameter of different samples, the wet/dry (K) ratios of DM test values were calculated that are shown in the Figs. 9 to 11. In general, higher amounts of $\mathrm{K}$ in these three figures equivalents to the better resistance against moisture susceptibly. Making comparison between these three graphs, it could be found that limestone-mixtures conducted to a slightly higher $\mathrm{K}$ ratio rather than granite and RAP mixtures. Also HMA performed much better when using limestone aggregates. Almost all the common aggregate types which could be used in asphalt mixtures are acidic. Bitumen that is the other component of asphaltic mixtures is acidic too. Thus, in the presence of water, aggregates will to make a bond with water instead of binder. As aforementioned, RAP was considerably more acidic material that limestone and granite, and that is the reason lower $\mathrm{K}$ values were achieved for RAP mixtures.

As a result, addition of PC and AP additives improved the deteriorated moisture susceptibility of cold mix asphalts slightly regarding $\mathrm{K}$ values in the Figs. 9 to 11 . All these conclusions by ITS and dynamic modulus tests were compatible with the achieved conclusions by SFE method to a high limit.

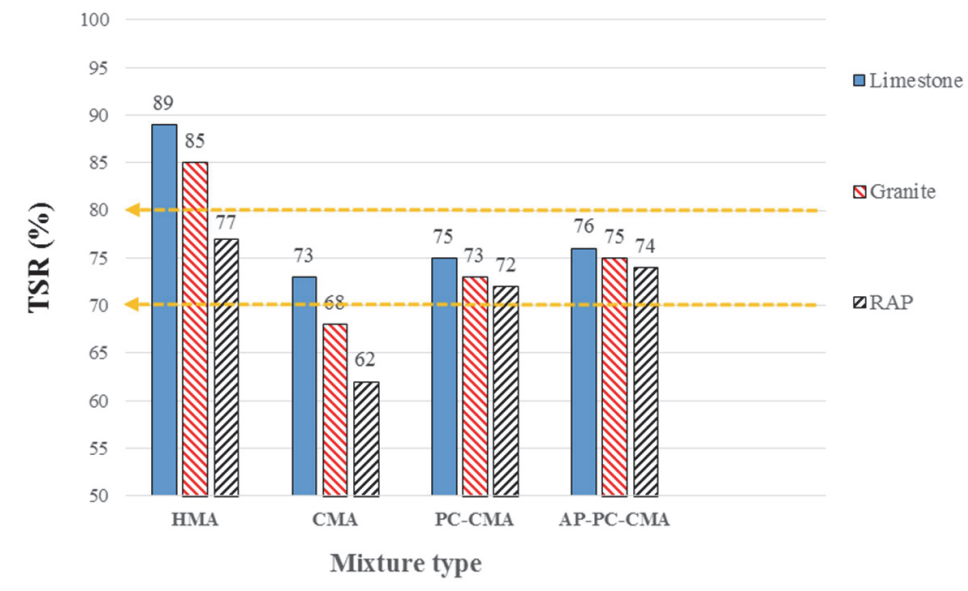

Figure 8: TSR values vs. mixture type.

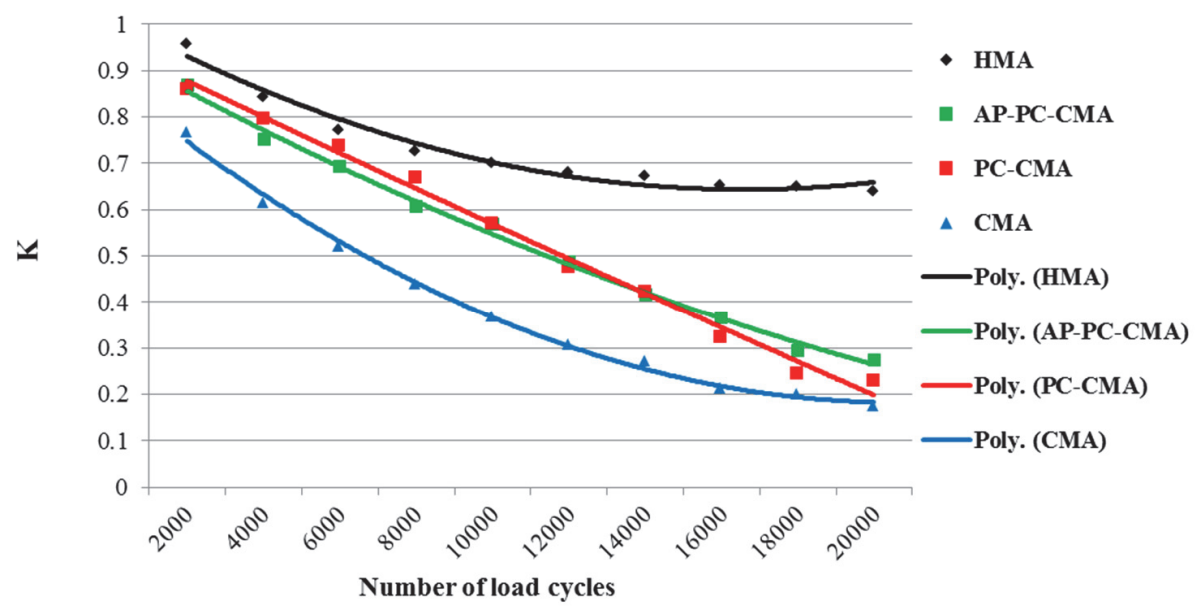

Figure 9: Dynamic modulus- wet/dry Ratios via number of cycles. (limestone). 


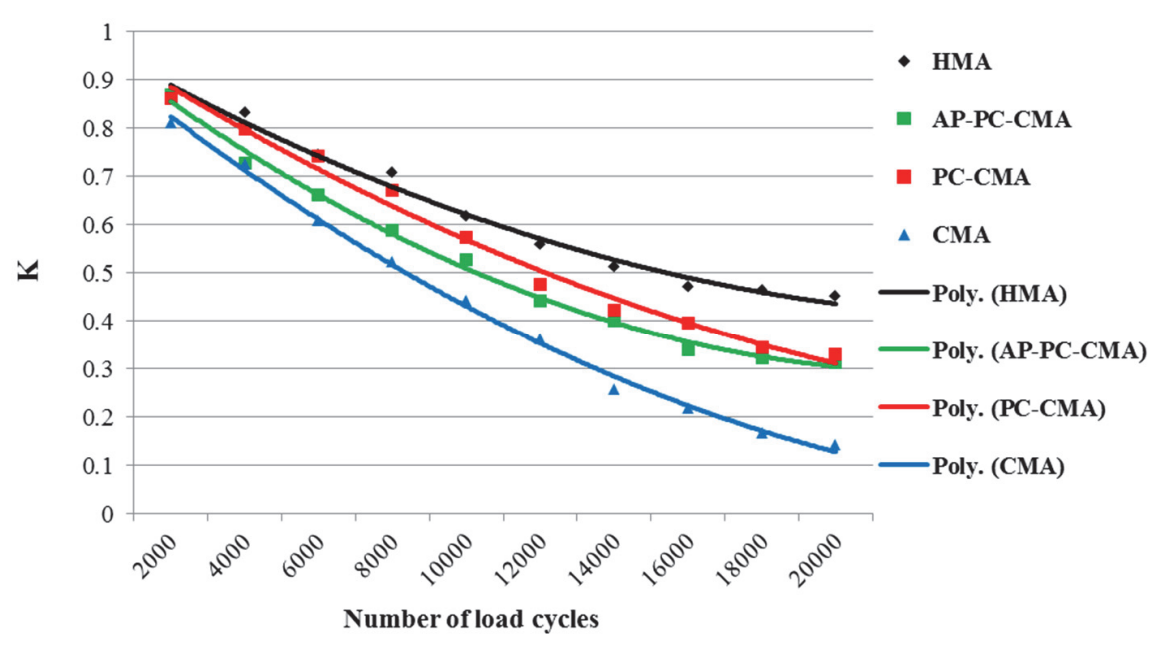

Figure 10: Dynamic modulus- wet/dry Ratios via number of cycles. (granite).

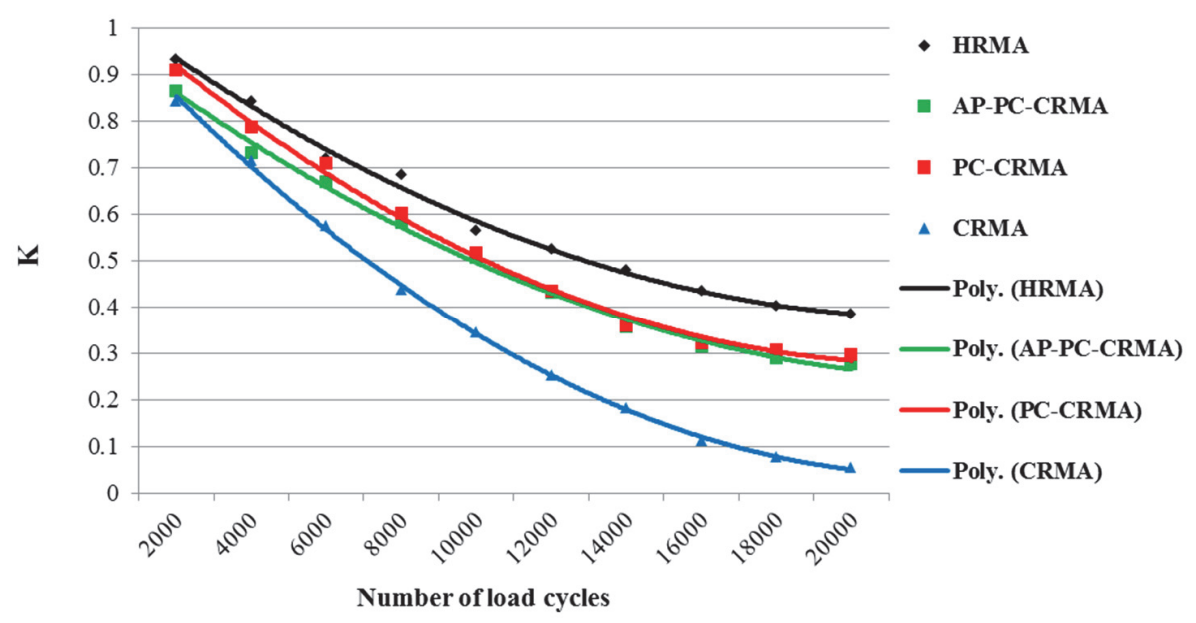

Figure 11: Dynamic modulus- wet/dry Ratios via number of cycles. (RAP).

\section{SEM Results}

To evaluate the morphology of prepared CRMA and consequently have an understanding about the quality of applied mixing process, SEM apparatus was used to take photos from CRMA as investigated sample and HMA/asphalt binder/PC paste, as reference samples. The samples were imaged under a Zeiss, Sigma VP environmental scanning electron microscope (SEM) in the backscattered mode to obtain high resolution micrographs that distinguishes different solid phases. As illustrated in Fig. 12, several high-resolution images were obtained at different magnifications from modified CRMA, unmodified CRMA and PC paste. SEM images of asphalt binder and PC paste are shown in Fig. 12.a and 10.b, respectively. In addition, SEM images of unmodified CRMA are shown in Fig. 12.c. In addition to CRMA, SEM photos were taken from raw asphalt and Portland cement to help having a better understanding about the shape of those materials in micro scale. By knowing the shape of those materials independently, distinguishing them from other ingredients could be easier and more precise. According to Fig. 12.d, it could be understood that asphalt emulsion, Portland cement, RAPs and polymeric additive were mixed properly, and a satisfying homogeneous CRMA was formed. As a result, applied mixing method was a successful one to make a homogeneous CRMA and no agglomeration was observed. 


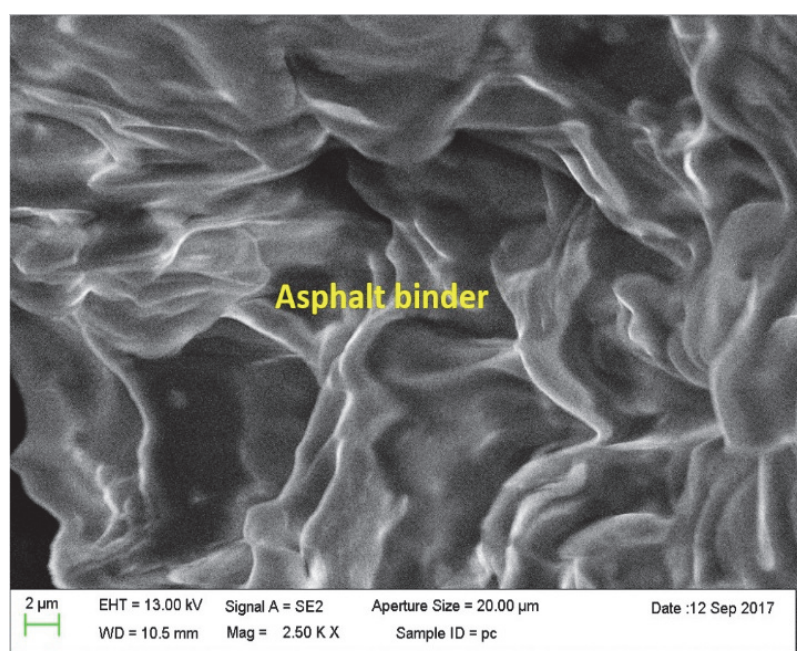

a)

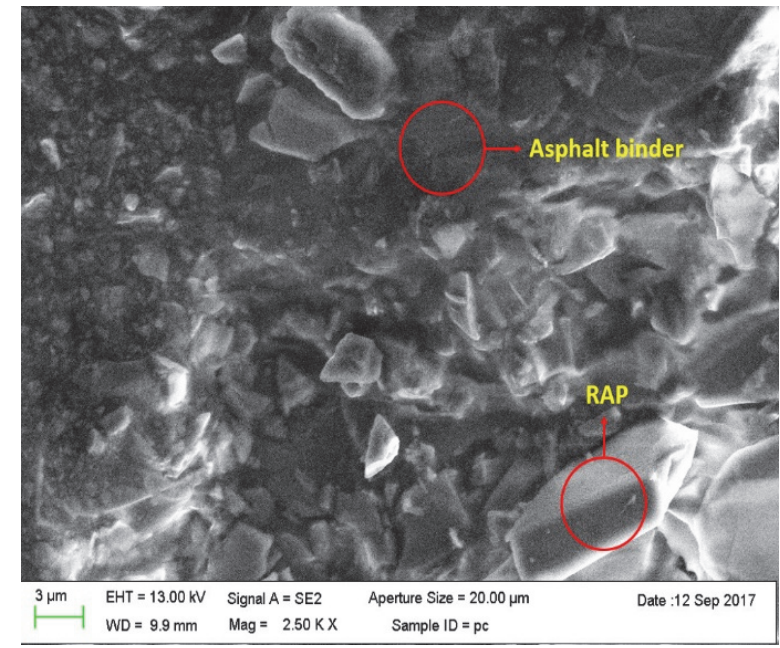

c)

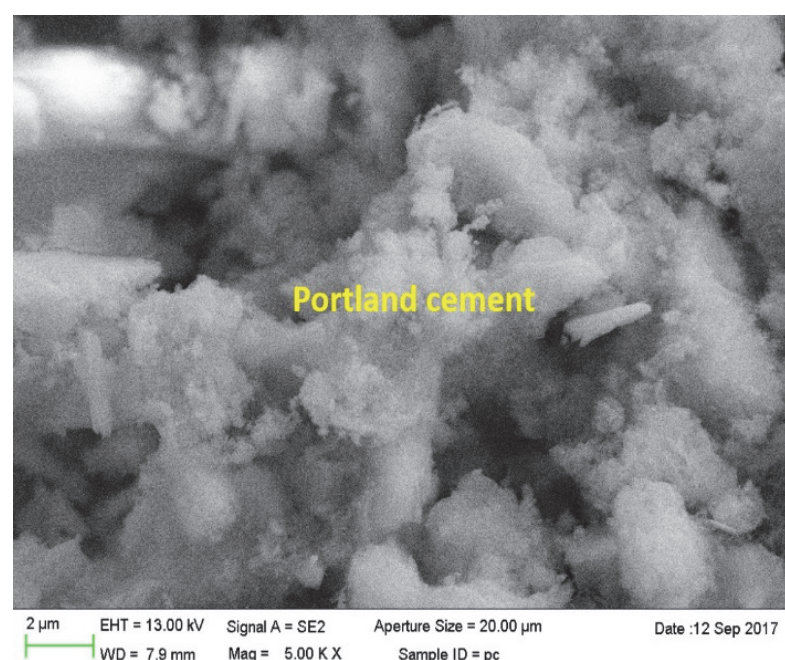

b)

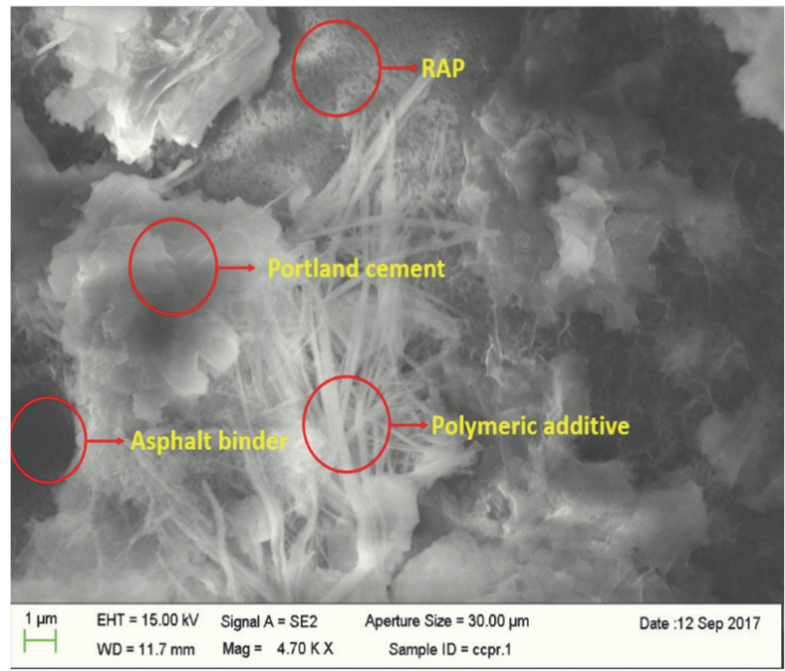

d)

Figure 12: SEM photos; a)HMA@2.5 kx, b)HMA@2.5kx, c) Portland cement@ 5 kx, d)CRMA@4.7kx

\section{CONCLUSIONS}

] $\mathrm{n}$ this study Portland cement and acrylic polymer were used as additives to improve the moisture susceptibility of CMA. To evaluate the effectiveness of this modification, SFE test and mechanical tests were conducted on modified CMA as main studied mixtures and unmodified CMA and HMA as reference mixtures. Asphalt mixtures were made with different combinations of binder and aggregates. The following conclusions could be drawn from the performed study:

- Lower Lifitz-van der Waal component of asphalt emulsion compared to PG 64-28 asphalt binder led to weaker SFE and consequently aggregates- binder adhesion.

- Addition of Portland cement (PC) and Acrylic Polymer (AP) to the asphalt emulsion increased acid-base component of SFE asphalt emulsion. Increased acid-base component led to higher free energy of adhesion for modified CMAs and consequently adhesion of cold mix asphalts improved.

- The findings showed that cement and acryl polymer additives improved resistance of different studied mixtures, specifically, cold recycled mix asphalt against moisture damage by improving the adhesion between aggregate and asphalt. 
- The adhesion energy between the bitumen and the granite aggregates was greater compared with limestone and RAP in dry condition, but limestone demonstrated lower free energy of adhesion in contact with water which made limestone-mixtures more resistant at wet condition in comparison with two other aggregates.

- Calculated compatibility ratios (CR) demonstrated higher values for limestone- mixtures in comparison with RAP and this ratio was higher for RAP than granite. The higher the CR ratio, the more resistance mixture against moisture induced distresses such as stripping.

- According to the SFE test results such as compatibility ratio (CR) and also operated mechanical test, the best function of asphalt mixtures against moisture damage obtained for HMA, PC-AP-CMA, PC-CMA and CMA respectively.

- The percentage of aggregate in contact with the water $(\mathrm{P})$ in different cycles of loading was almost the same for limestone and granite and considerably higher for RAP. Moreover, CMA showed the highest P value, while PC and AP modification improved this value slightly for modified- CMAs.

- The wet/dry ratios in dynamic modulus and ITS tests increased by addition of PC and AP additives, specifically for CMAs made with granite and RAP. It proved that used additives were more effective in improving moisture susceptibility of CMAs made with those two aggregates.

- Mechanical tests which were used to validate the SFE method displayed satisfying conclusions that makes this method more reliable to be used as a feasible way of moisture susceptibly evaluation for cold mix asphalts.

- As was observed in SEM images, applied mixing method was a successful one to make a homogeneous CRMA and no agglomeration was observed.

- It's Comprehensible that mixtures made by limestone had lower susceptibility against wet condition due to having higher TSR values in comparison with mixtures made by granite aggregates and RAP.

- Obtained results demonstrated the increase of TSR by PC and AP implementation for CMA. For instance, PC and AP additives improved TSR significantly by about $20 \%$ for CMA made by RAP aggregates. Therefore, moisture susceptibility of PC-AP-modified CMA was significantly improved compared to unmodified CMA. As a result, modification of CMA by the use of PC and AP was a successful method to reduce moisture susceptibility of CMA mixture.

- Considering effect of aggregates on moisture susceptibility, limestone-mixtures had the highest resistance while the RAP-mixtures performed the worst among the three. Finally, it was shown that results of SFE method were compatible with the mechanical tests in predicting moisture damage.

\section{REFERENCES}

[1] Cheng, L., Hanz, A., and Bahia, H. (2016). Measuring moisture susceptibility of Cold Mix Asphalt with a modified boiling test based on digital imaging, Construction and Building Materials., 105, pp. 391-399.

DOI: 10.1016/j.conbuildmat.2015.12.093.

[2] American Association of State Highway and Transportation Officials (AASHTO). (2013). Specifications and Testing Procedures.

[3] Asphalt Recycling \& Reclaiming Association. (2016). Recommended Mix Design Guidelines For Cold Recycling Using Emulsified Asphalt Recycling Agent.

[4] Cheng, L., Hanz, A. and Bahia, H. (2014). Evaluating Moisture Susceptibility of Cold-Mix Asphalt, Transportation Research Record: Journal of the Transportation Research Board., 2446, pp. 60-69. DOI: 10.3141/2446-07.

[5] Shafabakhsh, G. H., Faramarzi, M. and Sadeghnejad, M. (2015). Use of Surface Free Energy method to evaluate the moisture susceptibility of sulfur extended asphalts modified with antistripping agents, Construction and Building Materials., 98, pp. 456-464. DOI: 10.1016/j.conbuildmat.2015.08.123.

[6] Schultz, J., Nardin, M. (1999). Theories and mechanisms of adhesion. Materials Engineering-New York- 14, pp. 1-26.

[7] Bhasin, Amit. (2006). Development of Methods to Quantify Bitumen-Aggregate Adhesion and Loss of Adhesion Due to Water, Texas A\&M University.

[8] Golewski, Grzegorz Ludwik. (2018). Measurement of fracture mechanics parameters of concrete containing fly ash thanks to use of Digital Image Correlation (DIC) method, Measurement., 135, pp. 96-105.

DOI: 10.1016/j.measurement.2018.11.032. 
[9] Golewski, Grzegorz Ludwik (2019). Estimation of the optimum content of fly ash in concrete composite based on the analysis of fracture toughness tests using various measuring systems, Construction and Building Materials., 213, pp. 142-155. DOI: 10.1016/j.conbuildmat.2019.04.071.

[10] Recycling, A., \& Reclaiming Association. (2015). Basic asphalt recycling manual. Annapolis, Md, pp. $225-226$.

[11] Bernard, B. (1996). Polymer-modified asphalt cements used in the road construction industry: basic principles, Transportation Research Record: Journal of the Transportation Research Board., 1535, pp. 48-53. DOI: $10.1177 / 0361198196153500107$.

[12] Bhasin, Amit., Dallas N, Little. and Vasconcelos, Kamilla L. (2007). Surface Free Energy to Identify Moisture Sensitivity of Materials for Asphalt Mixes, Transportation Research Record: Journal of the Transportation Research Board., 2001(1), pp. 37-45. DOI: 10.3141/2001-05.

[13] Cindy, Estakhri., Button, Joe. and Alvarez, A. E. (2010). Field and laboratory investigation of warm mix asphalt in Texas, No. FHWA/TX-10/0-5597-2.

[14] Arabani, M., Roshani, H. and Hamedi, Gh. H. (2011). Estimating moisture sensitivity of warm mix asphalt modified with zycosoil as an antistrip agent using surface free energy method, Journal of Materials in Civil Engineering, 24(7), pp. 889-897. DOI: 10.1061/(ASCE)MT.1943-5533.0000455.

[15] Ghabchi, R., Singh, D., Zaman, M. and Tian, Q. (2013). Application of Asphalt-aggregates Interfacial Energies to Evaluate Moisture-induced Damage of Warm Mix Asphalt, Procedia-Social and Behavioral Sciences., 104, pp. $29-38$.

[16] Moghadas Nejad, F., Hamedi, Gh H. and Azarhoosh, A. R. (2013). Use of Surface Free Energy Method to Evaluate Effect of Hydrate Lime on Moisture Damage in Hot-Mix Asphalt, Journal of Materials in Civil Engineering, 25(8), pp. 1119-1126. DOI: 10.1061/(ASCE)MT.1943-5533.0000650.

[17] Arabani, M. and Hamedi, G. H. (2014). Using the surface free energy method to evaluate the effects of liquid antistrip additives on moisture sensitivity in hot mix asphalt, International Journal of Pavement Engineering., 15(1), pp. 66-78. DOI: $10.1080 / 10298436.2013 .778410$.

[18] Faramarzi, M., Golestani, B. and Lee, K. W. (2017). Improving moisture sensitivity and mechanical properties of sulfur extended asphalt mixture by nano-antistripping agent, Construction and Building Materials., 133, pp. 534-542. DOI: $10.1016 /$ j.conbuildmat.2016.12.038.

[19] Shah, Brij D. (2004). Evaluation of moisture damage within asphalt concrete mixes. Diss. Texas A\&M University.

[20] Oruc, Seref., Celik, Fazil. and Akpinar, M. Vefa. (2006). Effect of Cement on Emulsified Asphalt Mixtures, Journal of Materials Engineering and Performance, DOI: 10.1007/s11665-007-9095-2.

[21] Dingxin, C. (2002). Surface free energy of asphalt-aggregate system and performance analysis of asphalt concrete based on surface free energy. Diss. Texas A \& M University.

[22] Good, R. J. and Van Oss, C. J. (1971). The modern theory of contact angle and the hydrogen bond components of surface energies, Modern approach to wettability, Plenum, New York.

[23] Schapery, R. A. (1984). Correspondence principles and a generalized integral for large deformation and fracture analysis of viscoelastic media, International Journal of Fracture., 25(3), pp. 195-223.

[24] Bhasin, A. and Little, D. N. (2007). Characterization of aggregate surface energy using the universal sorption device, Journal of Materials in Civil Engineering., 19(8), pp. 634-641.

DOI: 10.1061/(ASCE)0899-1561(2007)19:8(634).

[25] Hefer, A. W., Bhasin, A. and Little, D. N. (2006). Bitumen surface energy characterization using a contact angle approach, Journal of Materials in Civil Engineering., 18.6: 759-767. DOI: 10.1061/(ASCE)0899-1561(2006)18:6(759).

[26] Wei, J., Dong, F., Li, Yanan. and Zhang, Y. (2014). Relationship analysis between surface free energy and chemical composition of asphalt binder, Construction and Building Materials., 71, pp. 116-123. DOI: $10.1016 /$ j.conbuildmat.2014.08.024.

[27] Arabani, M. and Hamedi, Gh. H. (2010). Using the surface free energy method to evaluate the effects of polymeric aggregate treatment on moisture damage in hot-mix asphalt, Journal of Materials in Civil Engineering, 23(6), pp. 802811. DOI: 10.1061/(ASCE)MT.1943-5533.0000228.

[28] Yiqiu, Tan. and Guo, Meng. (2013). Using surface free energy method to study the cohesion and adhesion of asphalt mastic, Construction and Building Materials., 47, pp. 254-260. DOI: 10.1016/j.conbuildmat.2013.05.067.

[29] Hamedi, Gh. H. and Moghadas Nejad, F. (2014). Using energy parameters based on the surface free energy concept to evaluate the moisture susceptibility of hot mix asphalt, Road Materials and Pavement Design, pp. 239-255. DOI: $10.1080 / 14680629.2014 .990049$. 